\title{
STRUCTURAL RESPONSE AND FAILURE OF A FULL-SCALE STITCHED GRAPHITE-EPOXY WING
}

\author{
Dawn C. Jegley and Harold G. Bush \\ NASA Langley Research Center \\ Hampton, VA \\ Andrew E. Lovejoy \\ Analytical Services and Materials Inc. \\ Hampton, VA \\ Presented at the AIAA/ASME/ASCE/AHS $42^{\text {nd }}$ Structures, \\ Structural Dynamics and Materials Conference
}

AIAA Paper No. 2001-1334-CP

Seattle, WA 
,

. , 


\title{
STRUCTURAL RESPONSE AND FAILURE OF A FULL-SCALE STITCHED GRAPHITE-EPOXY WING
}

\author{
Dawn C. Jegley" and Harold G. Bush * \\ NASA Langley Research Center, Hampton, Virginia 23681 \\ and \\ Andrew E. Lovejoy \\ Analytical Services and Materials Inc., Hampton, Virginia 23666
}

\begin{abstract}
Analytical and experimental results of the test for an all-composite full-scale wing box are presented. The wing box is representative of a section of a 220 passenger commercial transport aircraft wing box and was designed and constructed by The Bocing Company as part of the NASA Advanced Subsonics Technology (AST) program. The semi-span wing was fabricated from a graphite-epoxy material system with cover panels and spars held together using Kevlar stitches through the thickness. No mechanical fasteners were used to hold the stiffeners to the skin of the cover panels. Tests were conducted with and without lowspeed impact damage, discrete source damage and repairs. Up-bending, down-bending and brake roll loading conditions were applied. The structure with nonvisible impact damage carried $97 \%$ of Design Ultimate Load prior to failure through a lower cover panel access hole. Finite element and experimental results agree for the global response of the structure.
\end{abstract}

\section{Introduction}

One of NASA's goals is to reduce the cost of air travel by $50 \%$ in the next 20 years. To achieve this goal, NASA has been involved in the development of the technologies needed for future low-cost, lightweight composite structures for commercial transport aircraft. As a consequence of this effort, a stitched graphite-epoxy material system has been developed with the potential for reducing the weight and cost of

\footnotetext{
* Senior Aerospace Engineer, Mechanics and Durability Branch. Senior Member, AIAA.

Senior Aerospace Engineer, Mechanics and Durability Branch. Associate Fellow, AIAA.

Senior Aerospace Engineer, Analytical Services and Materials, Inc. Senior Member AIAA.
}

Copyright $(1001$ by the American Institute of Aeronautics and Astronautics, Inc. No copyright is asserted in the United States under Title 17, U.S. Code. The U.S. Government has a royalty-free license to exercise all rights under the copyright claimed herein for Governmental purposes. All other rights are reserved by the copyright owner. commercial transport aircraft wing structure. By stitching through the thickness of a dry graphite-epoxy material system, the labor associated with wing cover panel fabrication and assembly can be significantly reduced. By stitching through the thickness of prestacked skin and then stitching together stringers, intercostals and spar caps with the skin, the need for mechanical fasteners is almost eliminated. This manufacturing approach reduces part count, and therefore, the manufacturing cost of the structure.

In order to explore fully the manufacturing aspects of this new material system, a 41-foot-long wing box was fabricated by the Boeing Company as part of the NASA Advanced Subsonic Technology Program. A complete description of the wing box is presented in reference 1 and a summary of the NASA/Boeing program is presented in reference 2 .

This wing box represents the load-carrying wing box of a 220-passenger commercial transport aircraft. Though originally conceived as a manufacturing development article since the stitched, resin-film-infusion (RFI) process had never been used on a composite structure of this size and complexity, the wing was designed to withstand loads associated with several flight conditions. The most critical loading conditions examined were $-1 \mathrm{G}$ downbending, $2.5 \mathrm{G}$ upbending and a brake roll runway condition where twist is applied through the simulated landing gear leg. The wing box was loaded in a series of tests covering all threc load conditions and then loaded to failure at the NASA Langley Research Center. Included in the test series were tests to evaluate the hehavior of the wing box when subjected to nonvisible impact damage, discrete source damage and repair. A photograph of the wing prior to testing is shown in figure 1. Nine load introduction locations are shown in the figure and load was applied by pushing up on the wing or pulling down on the wing, depending on the load case. The present paper focuses on the final loading of the test article in the $2.5 \mathrm{G}$ upbending condition.

\section{Wing-Box Test-Specimen Description}

The wing box cover panels and spars were fabricated from stiched/resin film infused graphiteepoxy material, minimizing the number of mechanical fasteners needed to assemble the wing box. The 
composite upper cover skin and upper cover bladestiffeners were composed of layers of graphite material forms that were prekitted in nine-ply stacks using Hercules, Inc. AS4 fibers. Each nine-ply stack had a $\left[45 /-45 / 0_{2} / 90 / 0_{2} /-45 / 45\right]_{\mathrm{T}}$ laminate stacking sequence and was approximately 0.055 -inches thick. The composite lower cover panel skin was composed of 0 degree layers of Hercules, Inc. IM7 fibers and \pm 45 -and 90-degree layers made from AS4 fibers. Prekilled stacks were assembled in a similar manner as for the upper cover panel skin. Several stacks of the prekitted material were used to build up the desired thickness at each location. Skin thickness ranged from 0.265 to 0.605 inches. Upper cover stringer blades ranged in thickness from 0.44 to 0.605 inches. Braided stringers, as described in reference 1, of AS4 fibers were used in the lower cover panel. Braided stringer blades ranged in thickness from 0.48 to 0.768 inches and contain \pm 60 degree braids. All material was stitched together using E. I. DuPont de Nemours, Inc. Kevlar ${ }^{\text {th }}$ thread. Stiffener flanges for stringers in the spanwise direction, intercostals in the chordwise direction and spar caps along the forward and aft edges of the cover panels were stitched to the skin and no mechanical fasteners were used for joining. The composite wing box was fabricated using Hercules, Inc. 3501-6 epoxy in a Resin Film Infusion (RFI) process which is described in references 3 and 4 . Stitched graphite-epoxy spars with the same stacking sequence and material as the upper cover panel skin were mechanically attached to the spar caps. Tape-laid graphite-epoxy ribs were mechanically fastened to the intercostals to create the 41 -foot-long wing box. Sketches of the upper and lower cover panels are shown in figures $2 a$ and $2 b$, respectively. Eighteen ribs and ten stringers are identified by number in figure 2. Holes are identified by hole number starting with the most inboard hole.

The upper and lower cover panels each contain five stringer terminations or runouts. Blade and flange thicknesses are reduced by removing two stacks of material at a time, at three-inch intervals in all runouts. Lower cover stringers terminating at ribs 8,10 , and 15 and the upper cover stringers terminating at rib 9 have a tapered height blade, as shown in figure $3 a$. The lower cover stringer terminating at rib 4 and the upper cover stringers terminating at ribs 4 and 15 have a constant height blade and terminate by folding the last two stacks of stringer material against the intercostal as shown in figure $3 \mathrm{~b}$. The upper cover panel blade height is tapered from a maximum of between 2.5 and 3.25 inches to zero at a taper angle of 8 degrees. The lower cover panel blade height is tapered from a maximum of between 2.65 and 3.5 inches to zero at a taper angle of $1 \mathrm{I}$ degrees.

Finally, load introduction hardware was attached to the wing box prior to shipment to NASA
Langley Research Center. The load introduction hardware included fixtures at each of the actuator attachment locations, metal landing gear doublers on the upper and lower cover panels and a root mount transition box that provided a method of attaching the wing box 10 the load wall in the test facility. Upon installation at the test facility, a simulated landing gear leg was attached to the doubler assembly through the use of two 9-inch-diameter steel bolts.

\section{Mounting and Loading Apparatus}

Each actuator/load cell assembly 1-9 was connected to the floor and to the test article through swivels which would allow the actuator to rotate as the wing box deformed. This rotation prevented the introduction of localized bending loads into the wing lower surface at load introduction points $1-8$ shown in figure 1. A sketch of the loading assembly for a typical actuator is shown in figure 4 . The landing gear region includes three actuator assemblies as described in detail in reference 5 but are not described herein since only vertical actuators were active during the $2.5 \mathrm{G}$ loading tests.

\section{Loading Sequence}

The wing structure was subjected to eight tests with three load conditions as listed in table 1 . These conditions are "brake roll," $-1 \mathrm{G}$ and 2.5G. The brake roll load condition simulates a runway condition in which forces are applied primarily through the landing gear leg. The $-1 \mathrm{G}$ and $2.5 \mathrm{G}$ load conditions simulate extreme flight loading conditions. In the test the wing tip is pulled down to simulate a $-1 G$ flight maneuver and pushed up to simulate a $2.5 \mathrm{G}$ flight maneuver. The values of load at Design Limit Load (DLL) for each of these load conditions are shown in table 2 for all the load introduction points. Positive values in the table refer to pushing up on the wing and negative values refer to pulling down on the wing. Since these values simulate flight conditions, a combination of pushing up and pulling down is required in each load condition to achieve the desired wing motion.

First the test article was subjected to two brake roll tests, a $50 \%$ DLL test to verify accurate function of all components and instrumentation, followed by a $100 \%$ DLL test. Then two more 50\% DLL loadings were conducted to verify the accurate function of all components and instrumentation for the $-1 G$ and the 2.5G flight loading conditions. The wing was then loaded to $100 \%$ DLL in these two conditions.

After successful completion of all $100 \%$ DLL tests, discrete source damage was inflicted on the upper and lower cover panels of the wing. The wing was then loaded to $70 \%$ DLL in the $2.5 \mathrm{G}$ upbending condition 
and unloaded. Finally, the discrete source damage was repaired, six nonvisible impacts were inflicted, and the wing was loaded to failure in the $2.5 \mathrm{G}$ upbending load condition.

\section{Instrumentation and Control}

A computer control system and an independent computer data acquisition system were used during testing. Loading was increased slowly to a maximum with all actuators reaching the maximum loading simultaneously. Load rates varied among the different tests, but generally tests were planned to run for 15-30 minutes. Feedback signals were sent to the control system to keep the actuators loading evenly throughout each test. Data was recorded at the rate of once every second as load was applied during each test.

Displacements were measured using displacement transducers at each actuator location and at the two points on the lower surface where the root transition box connected to the composite box at the front and rear spar. 466 strain gages were used to record strains all over the test article. Locations of critical strain gages for the upper and lower cover panels are shown in figure 2. Strain gages shown at the access holes are on the edge of the hole at the midplane, not on the cover panel surface. All other gages were placed on the skin or stringer blade surface.

\section{Impact, Discrete Source Damage, and Repair}

Impact damage was inflicted by the use of a dropped-weight and an air-propelled projectiles.. Impact damage was inflicted to the upper and lower surfaces of the wing. Details of these damages are presented in reference 6 . A dropped-weight impactor was used to inflict three impacts with an energy level of $100 \mathrm{ft}-\mathrm{lbs}$ to the upper cover panel. The locations of these damage sites are shown in figure $2 \mathrm{a}$. A weight of $25 \mathrm{lbs}$ with a 1 -inch-diameter tup was dropped vertically from 4 feet, resulting in barely visible damage. The depth of the resulting damage ranged from 0.01 to 0.05 inches.

An air-propelled steel projectile was used to inflict three impacts with an energy level of 83-84 ft-lbs to the lower cover panel. The locations of these damage sites are shown in figure $2 \mathrm{~b}$. A steel sphere with a 0.5 inch diameter was accelerated to a speed of approximately $545 \mathrm{ft} / \mathrm{sec}$, resulting in clearly visible damage with dent depths up to 0.135 inches.

The wing was subjected to discrete source damage in the form of seven-inch-long sawcuts to the upper and lower cover panels, as shown in figure 2. Each sawcut ran through two stinger bays and cut through a stringer. Metal patch repairs were used to restore the wing to full load-carrying capability. The damaged region was removed prior to implementing the repair. The repairs consisted of a metal plate which conformed to the wing surface on the outer surface of the cover panels and internally spliced stringers. All parts of the repair were attached to the wing with mechanical fasteners.

\section{Finite Element Analysis}

A finite element analysis of the entire test article was conducted using the finite element code STAGS $^{h}$. The analysis accounts for geometric nonlinearities but not plasticity. Several versions of the finite element model were constructed, each with refined regions in the part of the structure of interest for a particular loading condition. Results for several of these models are presented in reference 7 covering studies conducted prior to testing. Only results from the post-test analysis of the $2.5 \mathrm{G}$ failure test, not presented in reference 7 , are presented herein.

All critical structural components are modeled using shell elements, including cover panels, spars, ribs stringers, the root mounting fixture, and the load introduction fixtures for actuators 1 through 4 . The load fixture for actuator 5 is modeled using offset beam elements. Beam elements are also used to model spar and web stiffeners, intercostals, bolts and actuators 1 through 4 . The stringer runouts are modeled in detail to accurately represent the taper in height and stack dropoffs. This detail is necessary to capture the local behavior in the region of the runouts. The finite element model for post-test analysis is shown in figure 5 which has approximately 71,000 nodes and 76,000 elements, for a total of approximatcly 428,000 degrees of freedom.

Due to the large deformations that occur on the outboard portion of the test article, and the possible effects of load orientation on the load fixture response, actuators I through 4 are included in the model. These actuators are represented by beams having no axial stiffness and high bending stiffness. The load (shown in table 2) for each actuator is then applied to the actuator beam end, and is treated as a follower force with respect to the actuator beam during the nonlinear analysis. The hase of the actuator beam is fixed in space at the floor location by setting all three translations of the base node equal to zero. The rotation about the global $y$-axis is also sel to zero to prevent rigid body motion. Proper orientation of the follower loads is ensured by requiring appropriate compatibility at the connection between the actuator beam and its load introduction fixture. This lechnique is discussed in detail in reference 7.

Post-test analysis is primarily concerned with understanding the behavior observed during the final test. Therefore, since the observed failure and measured 
nonlinearities occurred between ribs 8 and 9 , the model was highly refined between ribs 7 and 11 only.

\section{Results and Discussion}

Results are shown herein for the final test under the $2.5 \mathrm{G}$ load condition only, Test 8 . Analytical results for the undamaged test article subjected to brake roll and $-1 G$ conditions and the sawcut test article loaded in the $2.5 \mathrm{G}$ condition are presented in reference 7. Experimental results for lests in all three load conditions and with impact and discrete source damage are presented in reference 5 . No evidence of damage to the structure was detected in Tests 1-7. Analytical and experimental results for the final test are presented herein.

The test article supported $97 \%$ of its Design Ultimate Load (DUL) prior to failure in test 8. Design Ultimate Load is $150 \%$ of Design Limit Load. A photograph of the test article loaded at $95 \%$ DUL is shown in figure 6.

\section{Displacement}

Analytical and experimental displacements at the six most outboard actuator locations are shown in figure 7. Solid lines represent the measured displacements and dashed lines represent predicted displacements. Mcasured displacements are the elongation of the actuator rather than a measurement perpendicular to the floor. Since the initial position of all actuators active in the $2.5 \mathrm{G}$ condition is vertical, the difference between the displacement perpendicular to the floor and the stroke of the actuator is dependent upon the rotation of the actuator during loading. The largest displacement (and largest rotation) is for actuator 2 at the wing tip. The measured deflection is 40 inches and the initial position of the intersection of the actuator assembly and the test article is 168 inches above the floor. The angle between the initial vertical position of the actuator and the final tilted position can be calculated to be less than 2 degrees, resulting in a negligible difference between vertical displacement and stroke ${ }^{7}$.

Analytical results for the global displacements are within 8 percent of the experimental results for the final test.

\section{Strain}

The primary failure location is across the lower cover panel through access hole 4 . This region of the lower cover panel after final failure is shown in figure 8.
The failure goes through all stringers but primarily remains between ribs 8 and 9 . Both spars were also damaged. Other minor damage was found hut appears to be unrelated to the initial failure event. The discussion of the failure will be limited to the regions between ribs 6 and 10 .

Strain results presented herein follow a convention that negative values are compressive and positive values are tensile. All strain results are plotted against the load in actuator 2 . Upper cover panel and lower cover panel strains are presented. Locations of the strain gages of interest are shown in figure 2. Backto-back gages were placed on the outer surface of the cover panel skin and either the cover panel skin inner surface or the top of the stringer blade. Representative strain gage results are shown in figures 9 through 15 . In all strain result figures, solid lines represent measured strains and dashed lines represent analytical results.

Strains in the lower cover panel at stringer 4 between ribs 12 and 13 and at stringer 7 between ribs 7 and 8 are shown in figures 9 and 10 , respectively. Excellent correlation between experiment and analysis is seen in the skin between ribs 7 and 8 and in the stringer between ribs 12 and 13 until immediately prior to failure. The repair, which was not modeled in the analysis, is located between ribs 8 and 9 and may have some influence on these blade strains. Strains remain linear until immediately prior to failure. Strains in the lower cover runout of stringer 2 at rib 10 are shown in figure 11. Analytical strains at this runout agree well with experimental data.

Strains in the upper cover panel at stringer 6 between ribs 12 and 13 , at stringer 6 between ribs 9 and 10 , at stringer 2 between ribs 8 and 9 , and at stringer 8 between ribs 8 and 9 are shown in figures 12, 13, 14, and 15 , respectively. For most of thee cases, the agreement between analytical and experimental results is good. Excellent correlation between experiment and analysis is seen in the skin inboard from rib 12 and in the stringer outboard from rib 12 until immediately prior to failure. The repair, which was not modeled, is located between ribs 10 and 11 and may have some influence on experimental strain data. Strains do not remain linear in the upper cover panel. The maximum strains in any upper cover runout location are in the runout region at the rear spar at rib 9. Strains at this stringer runout 10.5 inches inboard from rib 9 are shown in figure 14. The blade is tapered in height as well as thickness at this location.

An overhang of the cover panels with a width of approximately four inches behind the rear spar left an unsupported edge along the length of the test article. This region is shown in figure $2 a$ as the "critical overhang region." A small initial geometric imperfection in the form of a kink in the upper cover panel was present in the as manufactured structure. 
This kink is centered half way between ribs 9 and 10 and has a maximum depth of 0.1 inches. The kink was initially considered minor enough that it would not influence the cover panel structural behavior. However, since the kink is in close proximity to a stringer runout and is in the region of the upper cover panel that displays nonlinear behavior, the kink influenced the behavior of the overhang region. Therefore, the kink was included in the post-test finite element model. This local refinement is shown in figure 16 . The kink is a geometric imperfection in the skin.

Calculated strains along the rear overhang of the upper cover for the outer and inner skin surfaces for load levels of $70 \%, 90 \%$ and $95 \%$ and $100 \%$ DUL are shown in figure 17. Reversal of strain occurs in several places along the exterior cover surface. Strain reversal for the outer skin surface occurs 6-8 inches outboard of rib 9. Strain reversal for the inner skin surface occurs from 1-4 inches inboard of rib 9 and 1.3-15 inches outboard of rib 9 . There were very few strain gages in this region, and hence experimental results are not presented.

Strain gages at the edges of the lower cover panel access holes indicate high strains at these locations. Measured strains at the outboard, rear corner of access holes 3 and 4 , between ribs 7 and 8 and ribs 8 and 9 , respectively, are presented in figure 18 . The strain gage locations are shown in figure $2 b$. Nonlinearity in the load-strain behavior can be seen at these access holes. The most significant nonlinearity is at the outboard corner of access hole 4. The largest measured strain is at this location and is approximately 0.0096 in./in. at DLL. Final failure of the cover panel ran through this location. Since analytical results to date do not adequately capture the failure, comparisons of these strains for the access hole edges are not done with experimental results.

\section{Concluding Remarks}

A 41-foot-long graphite-epoxy stitched wing box was tested in three load conditions and ultimately to failure. The test article is representative of a section of a 220-passenger commercial transport wing. The structure was fabricated using advanced manufacturing techniques to reduce cost, weight and improve damage tolerance capability. The test article sustained $97 \%$ of Design Ultimate Load prior to failure through a lower cover access hole which resulted in the loss of the entire lower cover panel. In addition to the high strains at the lower cover panel access holes, strain gage results indicate that local nonlinear deformations occurred in the upper cover panel in an unsupported region behind the rear spar. Experimental and analylical results are in good agreement for global behavior. Larger local displacements and strains occurred in the test than are predicted in the nonlinear finite element analysis. Further refinements to the finite element model might provide a better agreement of the analytical results with the test data.

\section{Acknowledgement}

The authors wish to express their thanks to William R. Doggett, William S. Small, and Cheri L. Bailey of NASA Langley Research Center and Byron L. Stonecypher of Wyle Laboratories for their support in the testing of the stitched semi-span wing.

\section{References}

1. Hawley, A., "Preliminary Design of a Transport Aircraft Composite Wing." Proceedings of the Fifth NASA/DoD Advanced Composites Technology Conference. NASA CP-3294, Volume 1, Part 2. pp. 717-772.

2. Karal, Michael, "AST Composite Wing Program Executive Summary," NASA CR 2001-210650.

3. Markus, A., Thrash, P., and Grossheim, B., "Manufacturing Development and Requirements for Stitched/RTM Wing Structure," NASA CP 3229, 1993, pp. 503-523.

4. Rohwer, K., Ghumman, A., and Markus, A., "Stitched/Resin Film Infusion (S/RFI)

Manufacturing Technology Development," Proceedings of the $11^{\text {th }}$ DOD/NASA/FAA Conference on Fibrous Composites in Structural Design. Report number WL-TR-97-3009 pp. XIII93-116.

5. Jegley, D. C. and Bush, H. G., "Structural Testing of a Stitched/Resin Film Infused Graphite-Epoxy Wing Box," NASA TM to be published in 2001 .

6. Rankin, C. C., Brogan, F. A; Loden, W. A., and Cabiness, H. D., "STAGS User Manual, Version 3.0." Lockheed Martin Missiles and Space Company, March 1999.

7. Lovejoy, A. E., "Finite Element Analysis of a Composite Semi-Span Test Article With and Without Discrete Damage," NASA CR 2000210308, August 2000. 
Table 1. Test sequence

\begin{tabular}{cr}
\hline Test number & Loading Condition \\
\hline 1 & $50 \%$ DLI., brake roll \\
2 & $100 \%$ DLL, brake roll \\
3 & $50 \%$ DLL, $-1 \mathrm{G}$ \\
4 & $50 \%$ DLL, $2.5 \mathrm{G}$ \\
5 & $100 \%$ DLL, $-1 \mathrm{G}$ \\
6 & $100 \%$ DLL, $2.5 \mathrm{G}$ \\
7 & $70 \%$ DLL $2.5 \mathrm{G}$ \\
8 & Failure $/ 150 \%$ DLL $2.5 \mathrm{G}$ \\
\hline
\end{tabular}

Table 2. Design Limit Load values for three load conditions

\begin{tabular}{crrr}
\hline $\begin{array}{c}\text { Actuator } \\
\text { position* }\end{array}$ & $\begin{array}{c}\text { Brake roll, } \\
\mathrm{lb}\end{array}$ & \multicolumn{1}{c}{$\begin{array}{l}-1 \mathrm{G}, \\
\mathrm{lb}\end{array}$} & $\begin{array}{c}2.5 \mathrm{G}, \\
\mathrm{lb}^{* * *}\end{array}$ \\
\hline $\mathrm{l}$ & -1000 & -6000 & 27000 \\
2 & -2000 & -30000 & 66500 \\
3 & -1000 & -22000 & -2000 \\
4 & -2000 & 8000 & 14000 \\
5 & -8000 & -6000 & 10000 \\
6 & -11500 & 11500 & -30000 \\
7 & 0 & -3000 & 30000 \\
8 & 10000 & -9500 & 4000 \\
9 & 124450 & 0 & 0 \\
\hline
\end{tabular}

*Actuator locations are shown in figure 1 .

** Positive load is due to pushing up and negative load is due to pulling down.

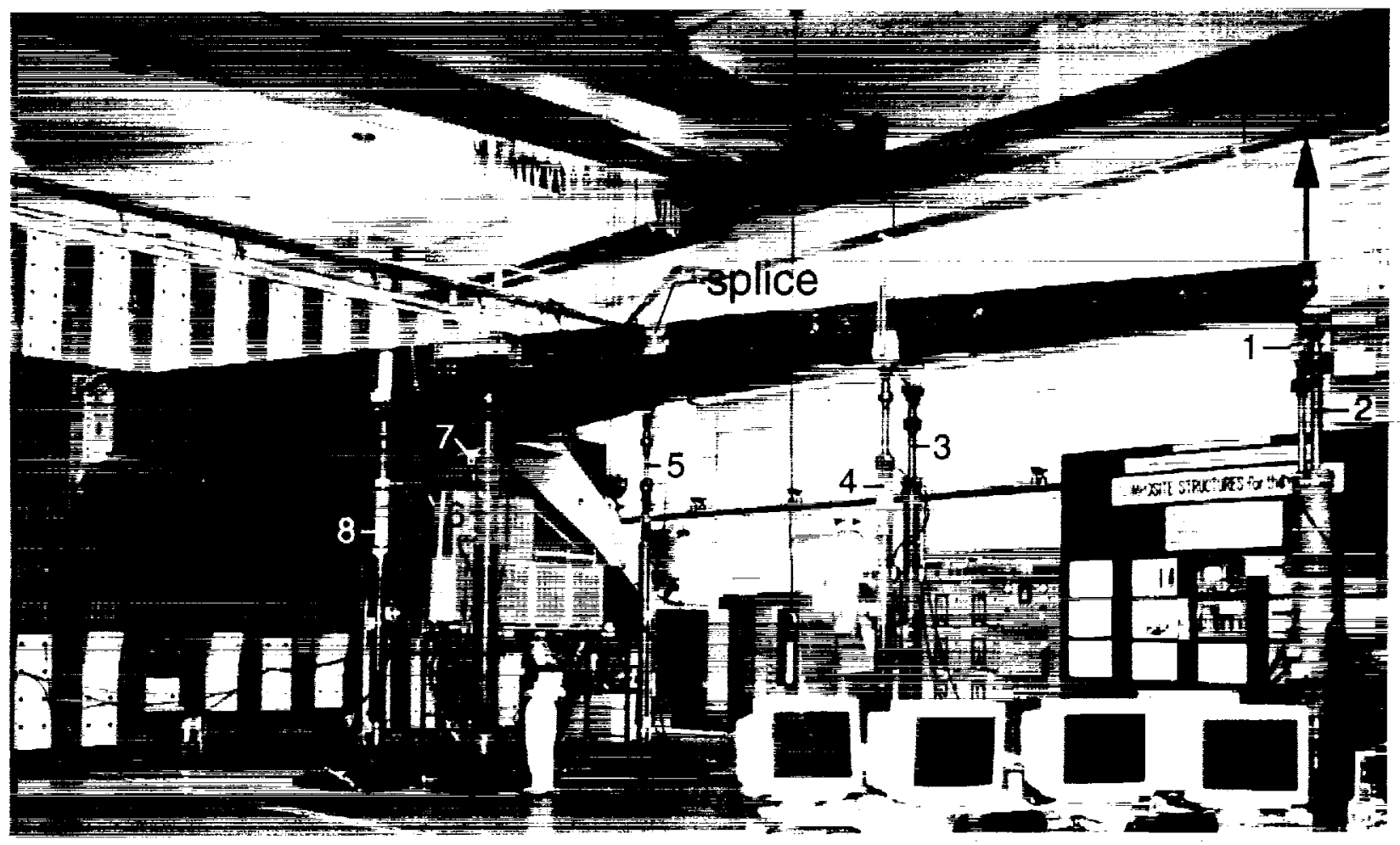

Fig. 1. Test article prior to testing. 


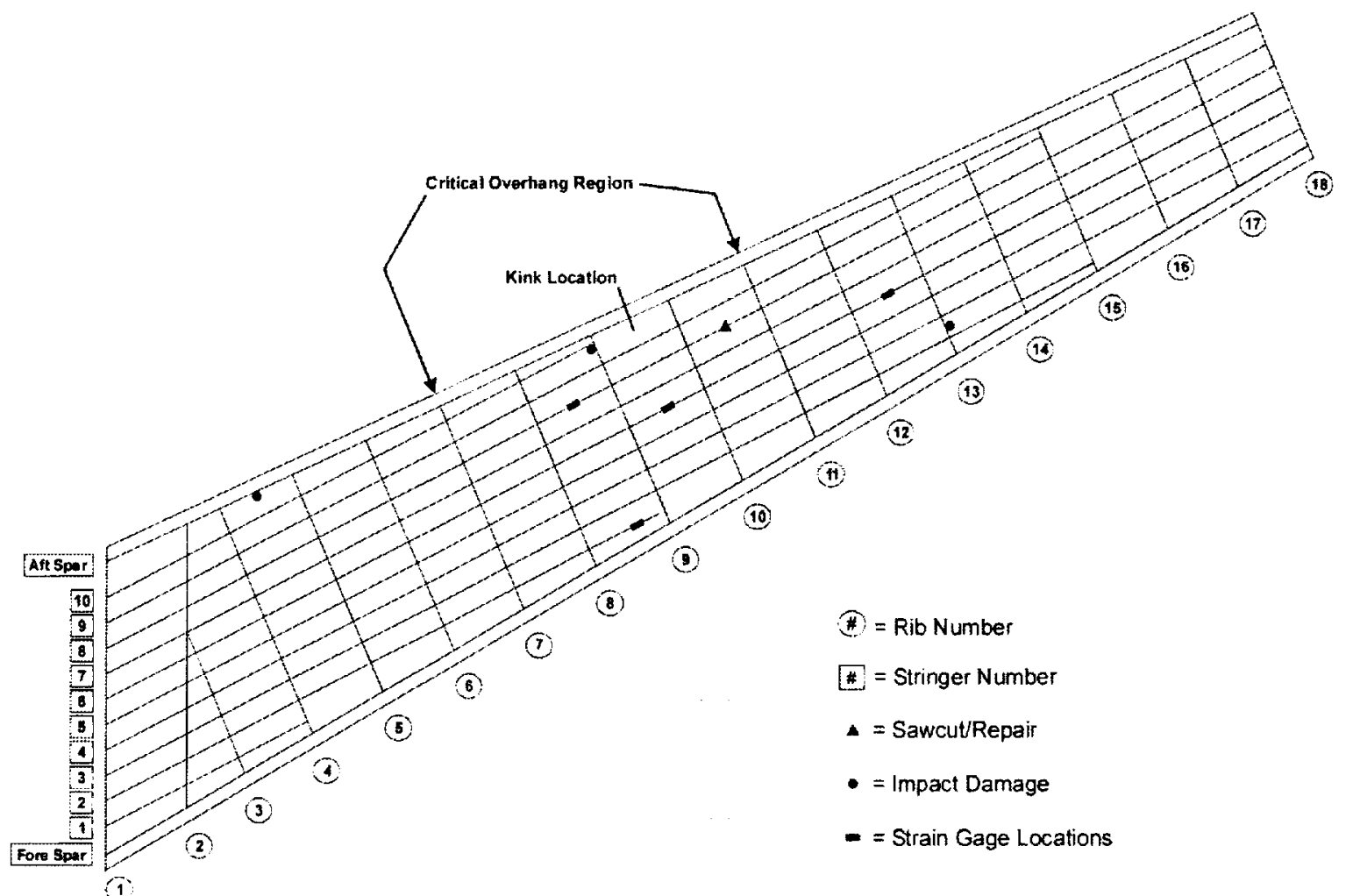

a) Upper cover panel

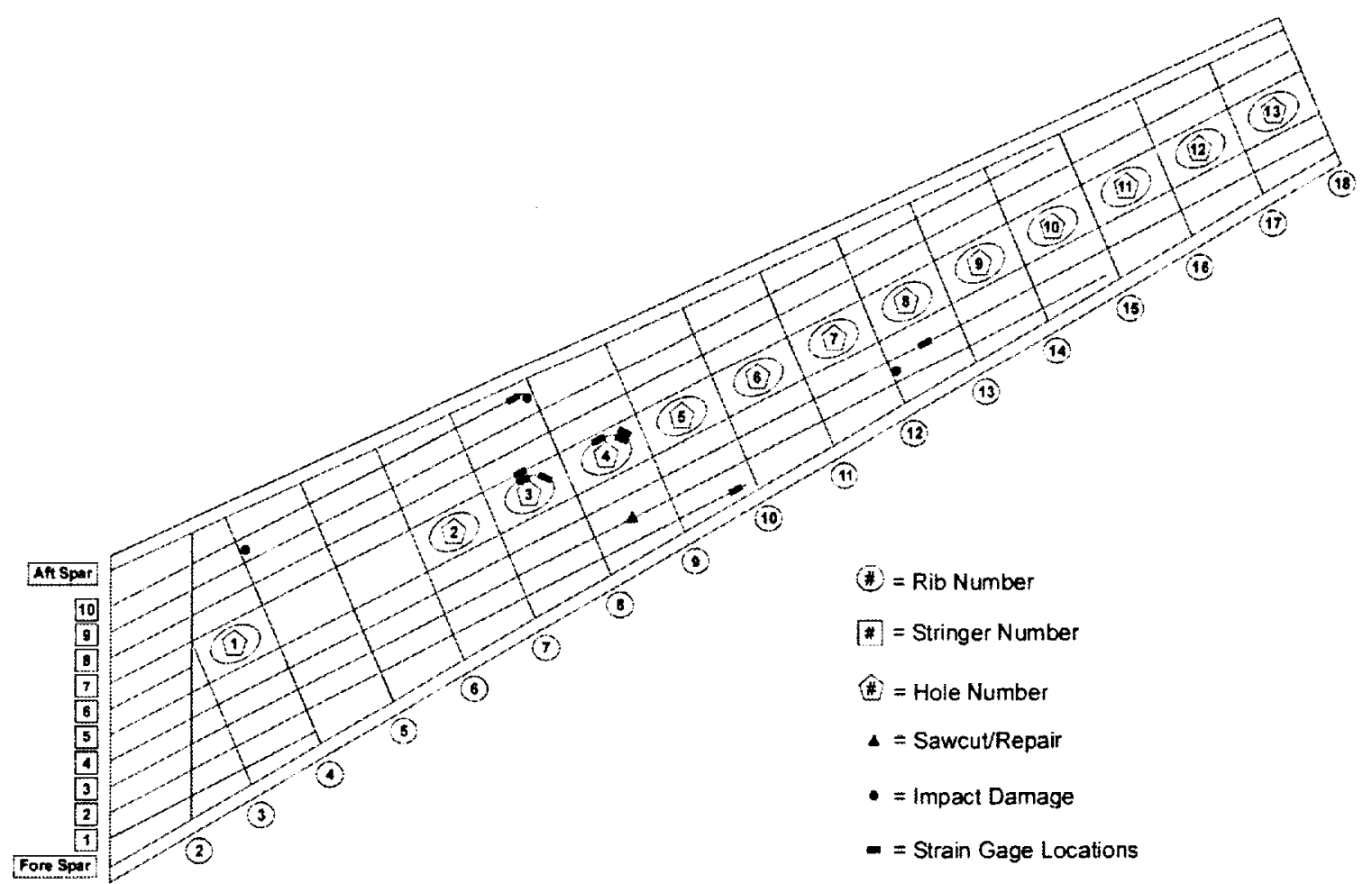

b) Lower cover pane]

Fig. 2. Upper and lower panel configuration and strain gage locations. 

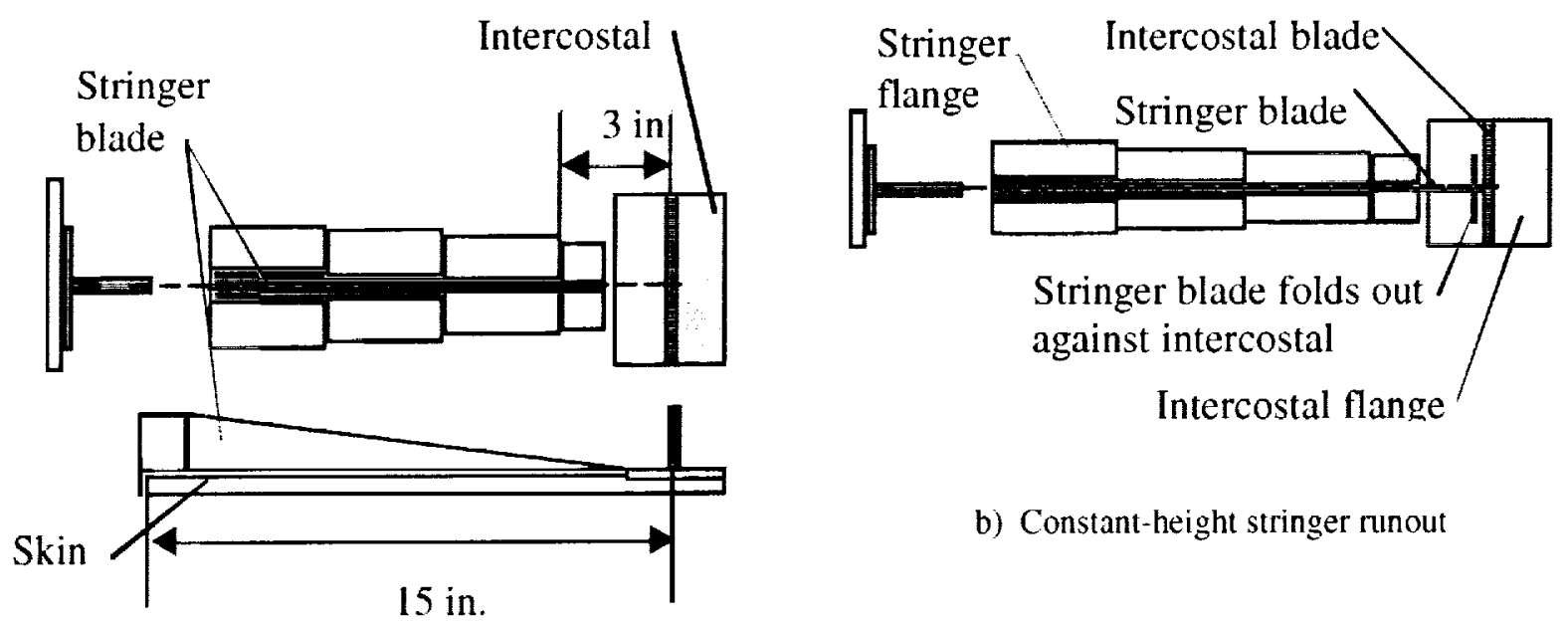

a) Tapered-height stringer runout

Fig. 3. Stringer termination configurations.

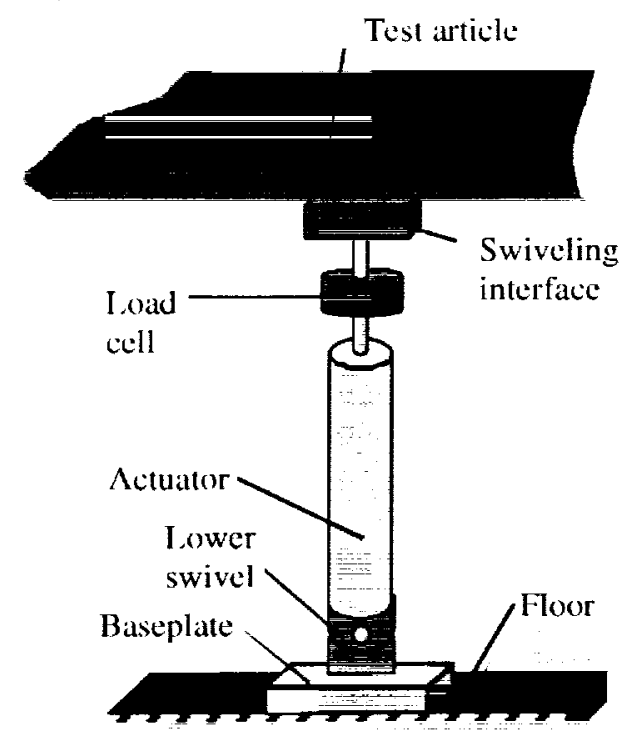

Fig. 4. Actuator/load cell assembly.

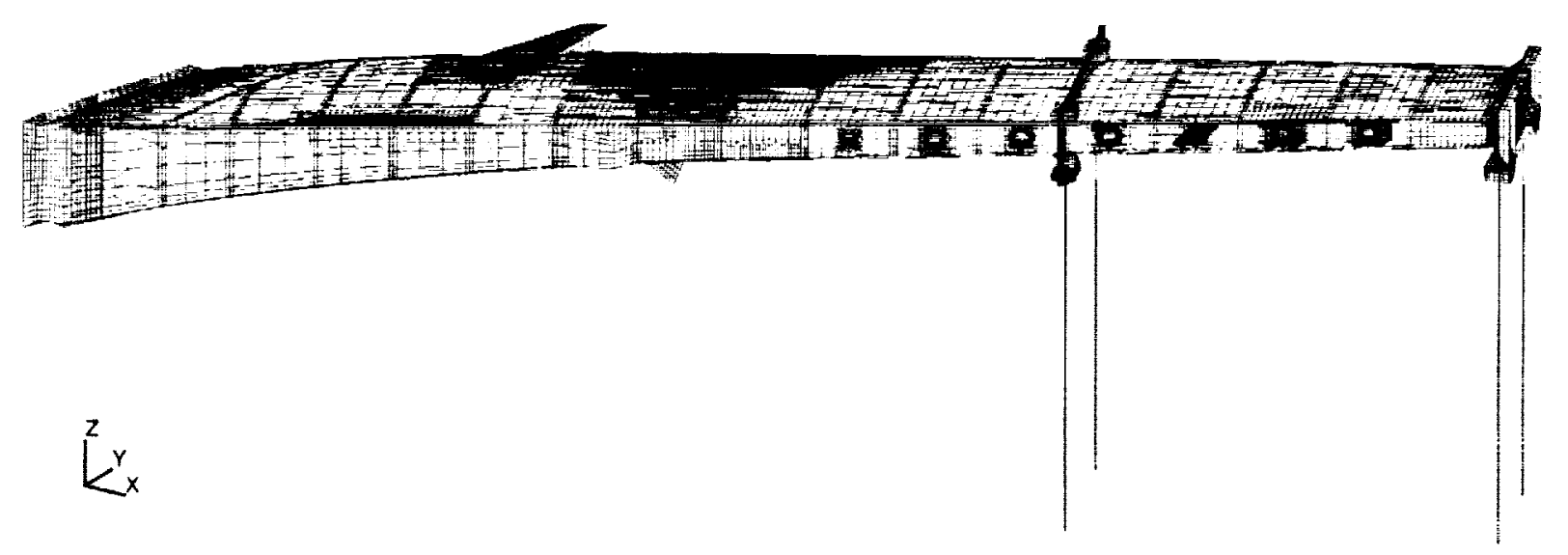

Fig. 5. Finite element model of test article. 


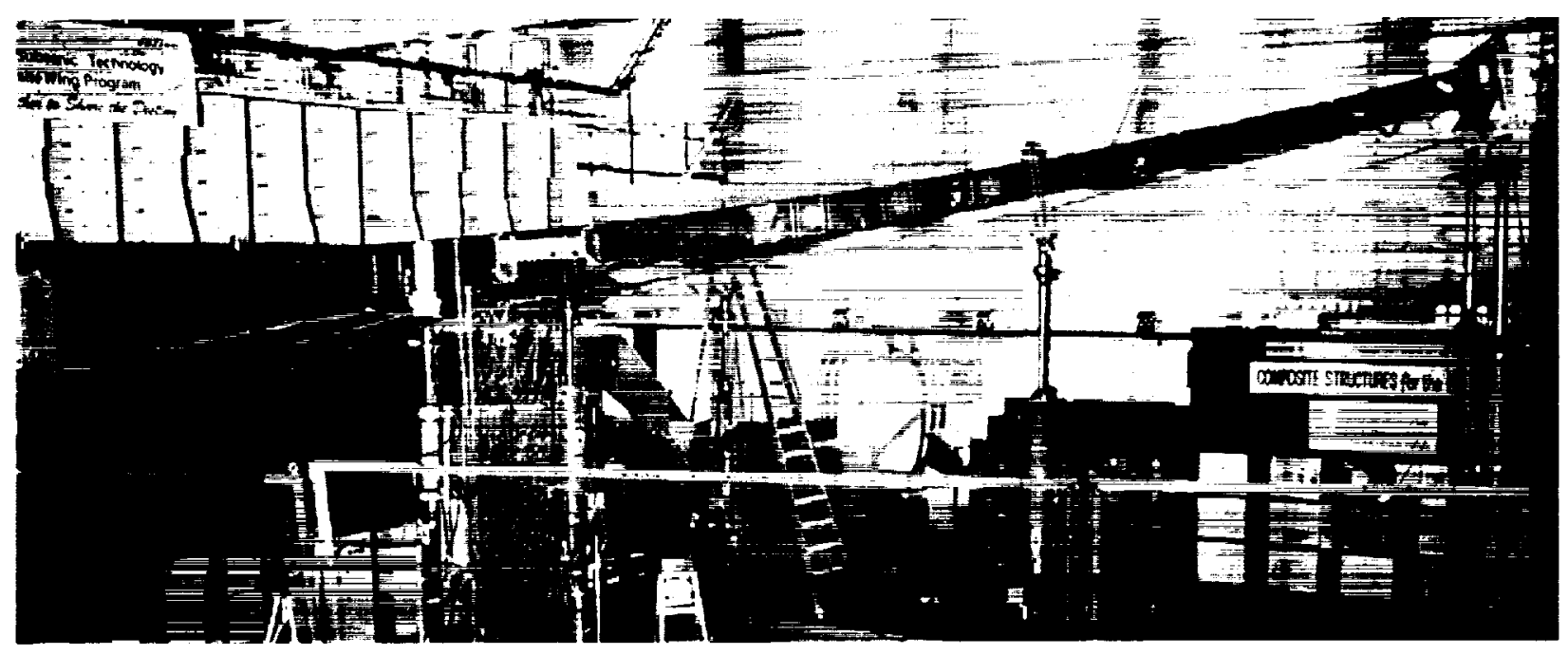

Fig. 6. Deformed test article loaded to 95\% of Design Ultimate Load.

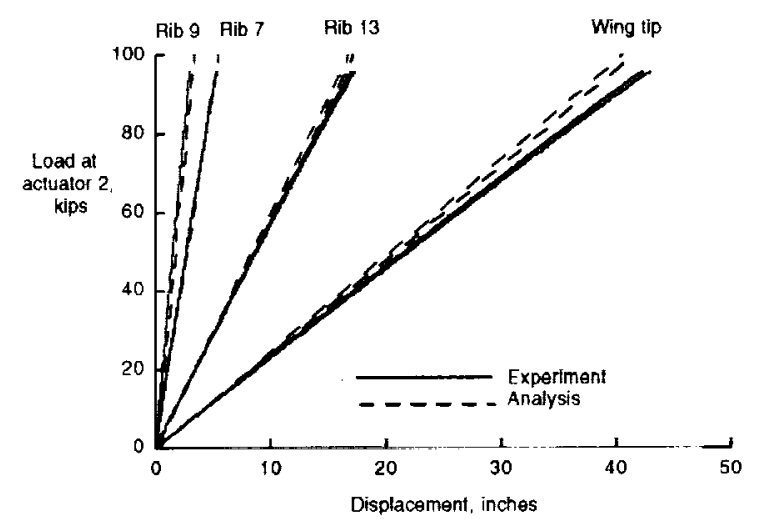

Fig. 7. Displacements at six outboard load introduction points.

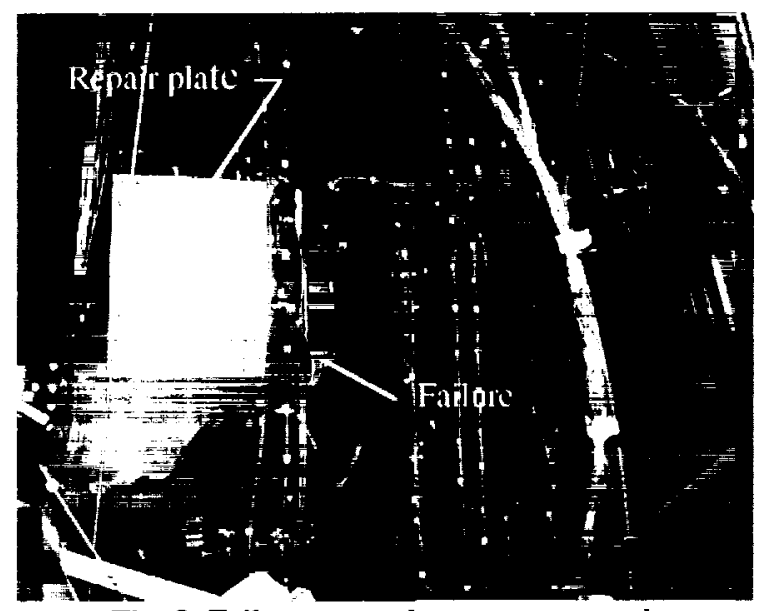

Fig. 8. Failure across lower cover panel.

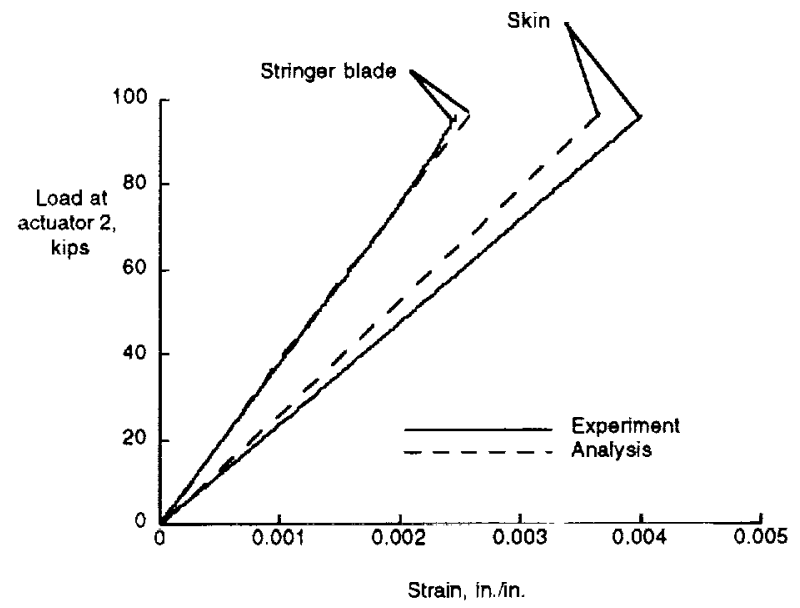

Fig. 9. Strain in stringer blade and skin at stringer 4 in the lower cover panel between ribs 12 and 13 .

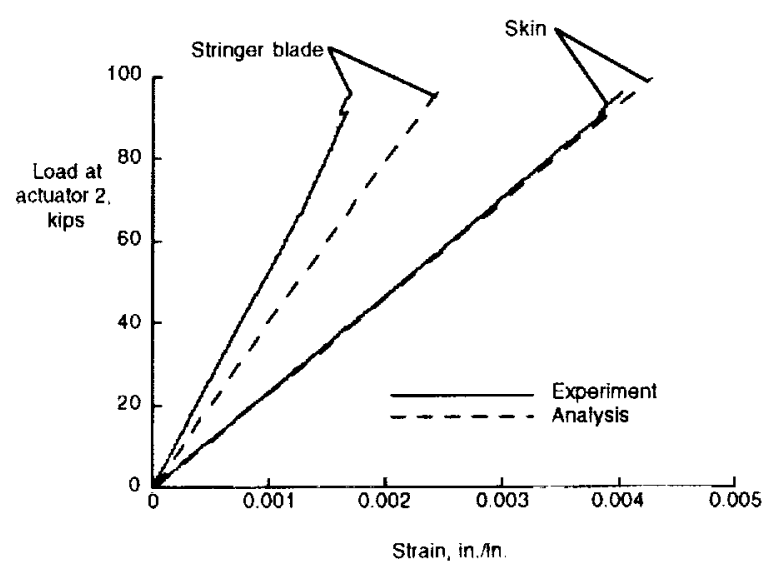

Fig. 10. Strain in stringer blade and skin at stringer 7 in the lower cover panel between ribs 7 and 8 . 


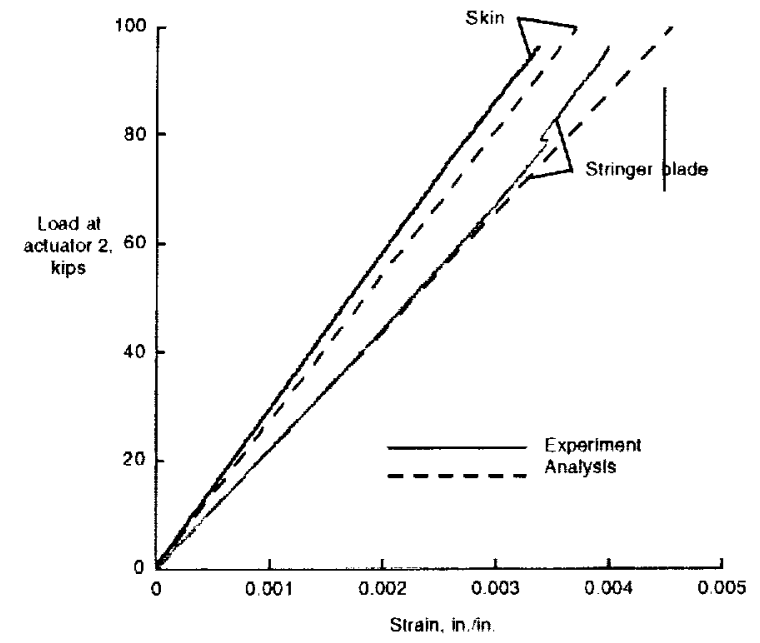

Figure 11. Strain in stringer blade and skin at stringer 2 in the lower cover panel between ribs 9 and 10 .

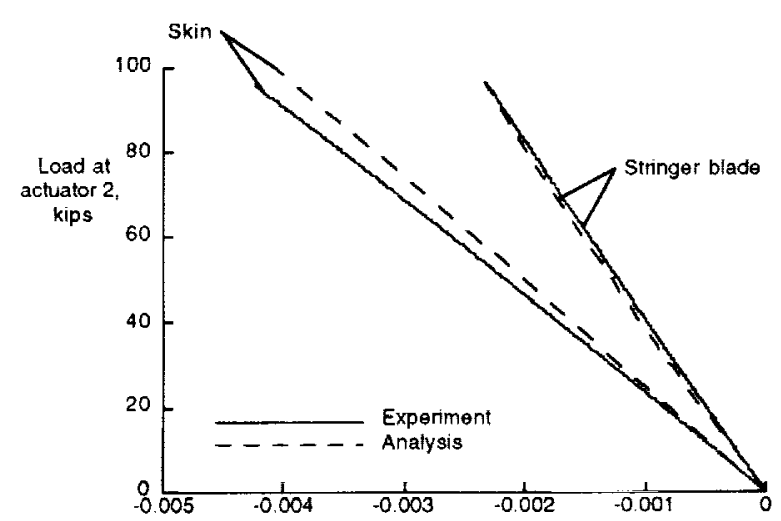

Fig. 12. Strain in stringer blade and skin at stringer 6 in the upper cover panel between ribs 12 and 13 .

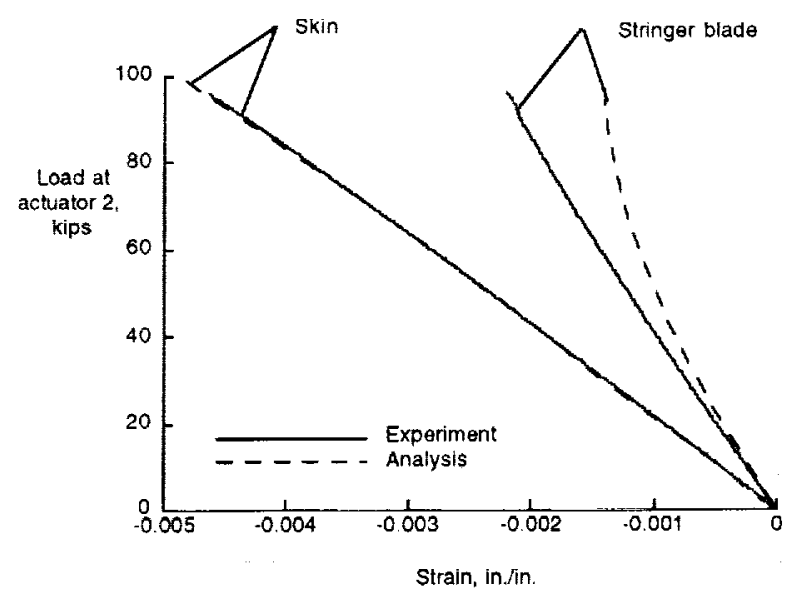

Fig. 13. Strain in stringer blade and skin at stringer 6 in the upper cover panel between ribs 9 and 10

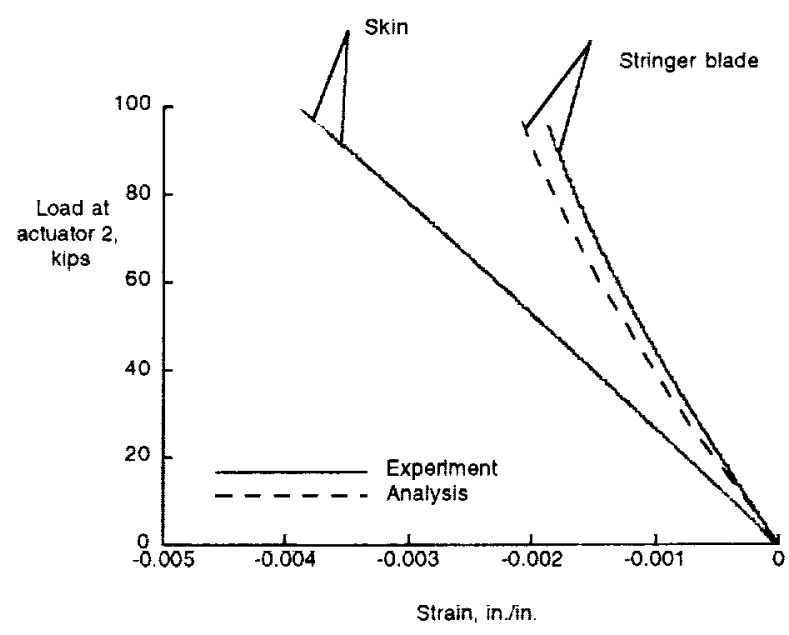

Fig. 14. Strain in stringer blade and skin at stringer 2 in the upper cover panel between ribs 8 and 9 .

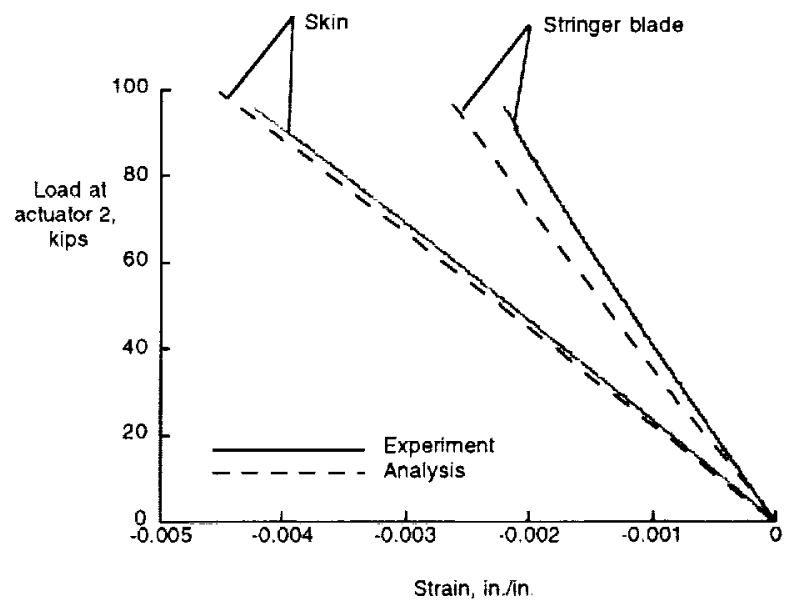

Fig. 15. Strain in stringer blade and skin at stringer 8 in the upper cover panel between ribs 8 and 9 . 


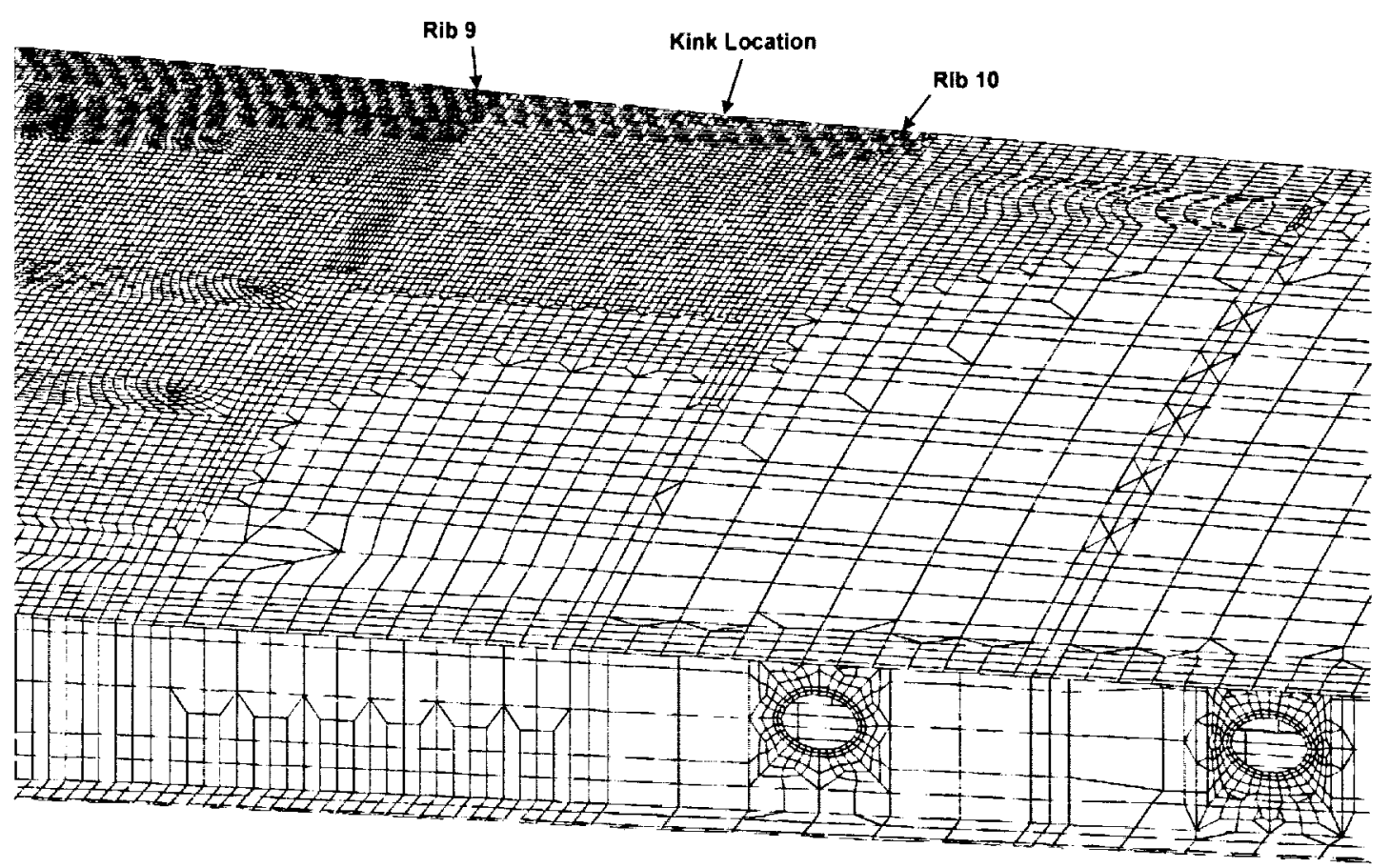

Fig. 16. Finite element model of kink region.

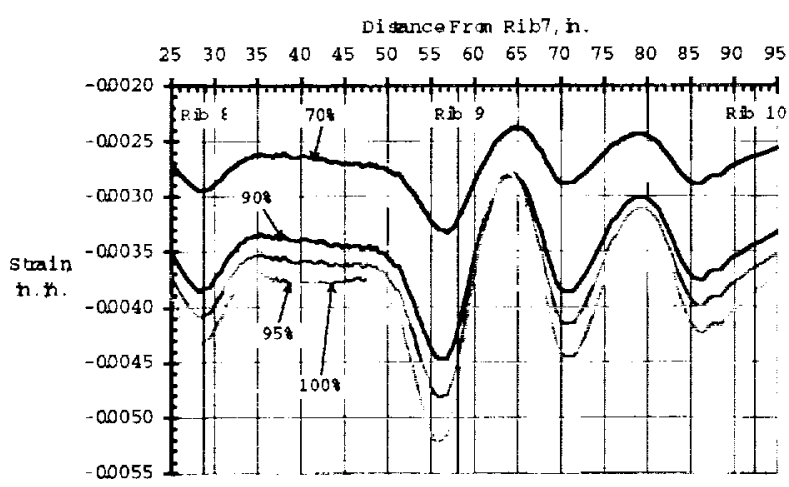

a) Exterior surface strains

Dis ance Frm $\mathrm{Rib} 7$, n.

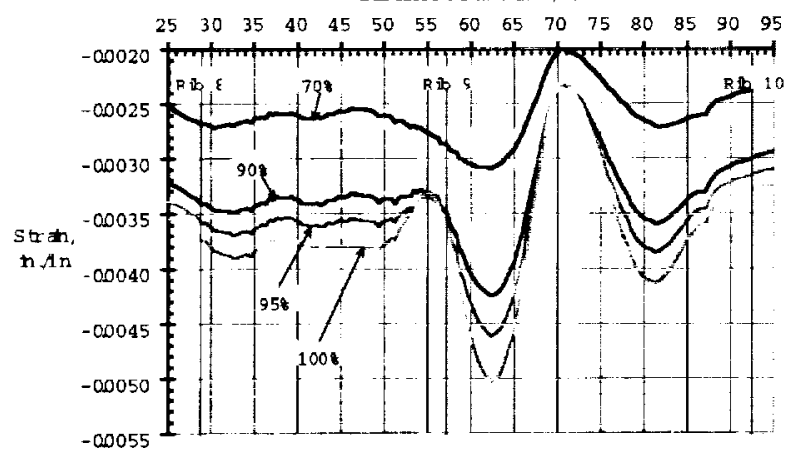

b) Interior surface strains

Fig. 17. Strains in the upper cover overhang region aft edge at several values of percent DUL.

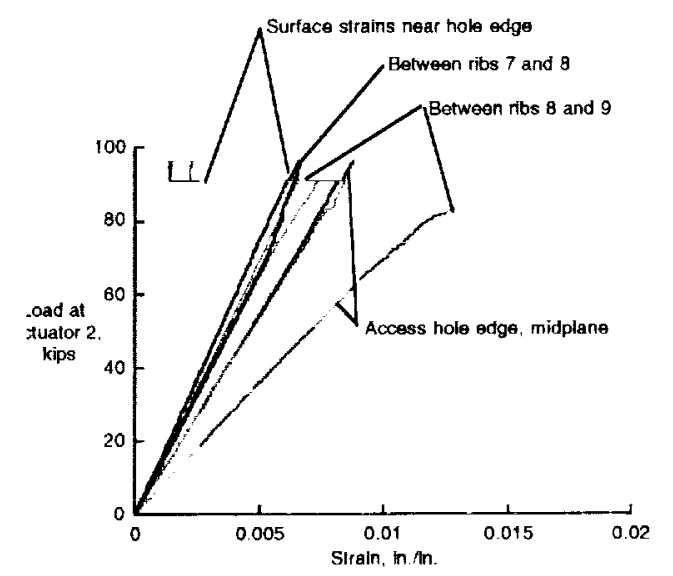

Fig. 18. Measured strain results at the edge of critical access holes. 
